\title{
Wetting and Bonding Behavior of SUS 304 Metal and Forsterite Ceramic with a $\mathrm{PbO}-\mathrm{Bi}_{2} \mathrm{O}_{3}-\mathrm{B}_{2} \mathrm{O}_{3}-\mathrm{ZnO}$ Glass Frit
}

\author{
Hang Choi ${ }^{1}$, Tadachika Nakayama ${ }^{2}$, Jin Sam Choi ${ }^{3, *}$ \\ ${ }^{1}$ Jinju Jungang High School, Jinju, Republic of Korea \\ ${ }^{2}$ Department of Electrical Engineering/Electronic Devices and Optical Electronics Group, Nagaoka University of Technology, Nagaoka, \\ Japan \\ ${ }^{3}$ Amorphous Keramos Institute Inc., Jinju, Republic of Korea
}

\section{Email address:}

sukyii34@naver.com (H. Choi),nky15@vos.nagaokaut.ac.jp (T. Nakayama),jinsamchoi03@gmail.com (J. S. Choi)

${ }^{*}$ Corresponding author

\section{To cite this article:}

Hang Choi, Tadachika Nakayama, and Jin Sam Choi. Wetting and Bonding Behavior of SUS 304 Metal and Forsterite Ceramic with a $\mathrm{PbO}-\mathrm{Bi}_{2} \mathrm{O}_{3}-\mathrm{B}_{2} \mathrm{O}_{3}-\mathrm{ZnO}$ Glass Frit. International Journal of Materials Science and Applications. Vol. 10, No. 1, 2021, pp. 8-11.

doi: $10.11648 /$ j.ijmsa.20211001.12

Received: August 12, 2020; Accepted: September 4, 2020; Published: February 23, 2021

\begin{abstract}
The joining behavior of metal to ceramic was investigated using glass frit media. Glass frit with a composition of $71.5 \mathrm{PbO}-24 \mathrm{Bi}_{2} \mathrm{O}_{3}-2.5 \mathrm{~B}_{2} \mathrm{O}_{3}-1.5 \mathrm{ZnO}-0.5 \mathrm{SiO}_{2}$ in mol. \% was designed to bond forsterite ceramic and SUS 304 metal. The glass frit demonstrated a glass transition temperature of $250^{\circ} \mathrm{C}$ and a thermal expansion coefficient of $15.9 \times 10^{-6} /{ }^{\circ} \mathrm{C}$, which isbetween the values of SUS $304\left(17.8 \times 10^{-6} /{ }^{\circ} \mathrm{C}\right)$ and forsterite $\left(9.9 \times 10^{-6} /{ }^{\circ} \mathrm{C}\right)$. The contact angle was smaller than $90^{\circ}$ at a temperature of $460^{\circ} \mathrm{C}$. Redox reaction at the interface between forsterite and SUS304 was found to appear when the electrons in the metal part moved toward the glass part and the oxygen ions in glass moved to the metal side. The decrease of the surface tension due to the $\mathrm{PbO}$ solubility on the forsterite side contributed to the better wetting behavior at low temperature. Due to the ionic bonding nature, the glass was able to chemically react with forsterite ceramic and form a rough boundary. The Fe metal in the SUS 304 was oxidized to form FeO ceramic. A thin FeO layer on the SUS 304 surface helped the glass frit to wet the SUS 304 , and clear tight bonding between the glass and SUS 304 was achieved.
\end{abstract}

Keywords: Forsterite, SUS 304, Thermal Expansion Coefficient (C.T.E), Ionic Bonding, Joining Glass to Metal

\section{Introduction}

Ceramic-metal bonding with glass frits has many applications such as in gas-containing tubes, electronic vacuum tubes, and electronic packaging. In order to bond the metal and ceramic with glass, the glass should wet both the metal and the ceramic $[1,2]$. This implies that, at the processing temperature, the glass should be somewhat fluid. The major problem with such bonds is mechanical fracture resulting from stress accumulated due to mismatch of the coefficients of thermal expansion (CTE) during the cooling process. Therefore, it is difficult to determine the right composition of glass needed to achieve the desired properties. To understand the bonding mechanism, though many experimental and theoretical studies have been conducted [3, 4], many issues still need to be resolved for specific applications. To fabricate an ionization chamber employing these bonds[5, 6], we designed the glass composition and examined the bonding behavior between metal SUS 304 and forsterite $\left(\mathrm{Mg}_{2} \mathrm{SiO}_{4}\right)$ ceramic with glass. Figure 1 shows photos of the ionization chamber and its components. To contain the inert gas inside the chamber, forsteritemust be tightly bonded with SUS 304 using the bonding glass. It is well known that forsterite is ideal for use in electronic tube parts and circuit substrates due to its low microwave loss, excellent insulation at high temperature, and smooth surface. In addition, forsterite has a suitable CTE so that it bonds easily with metals and glass [7, 8]. In this experiment, we determined the glass composition by combining $\mathrm{PbO}-\mathrm{B}_{2} \mathrm{O}_{3}-\mathrm{ZnO}$ and $\mathrm{Bi}_{2} \mathrm{O}_{3}-\mathrm{B}_{2} \mathrm{O}_{3}-\mathrm{ZnO}-\mathrm{SiO}_{2}$ glasses to result in a high thermal stability and processing temperature below $500^{\circ} \mathrm{C}$ [9]. The thermal and wetting behaviors of the glass were characterized at various temperatures. We successfully bonded SUS 304 and 
forsterite with glass and proposed the bonding mechanism based on the elemental distribution. Where SUS means steel use stainless.

\section{Experimental Procedure}

To characterize the wetting behaviors of the bonding glass on SUS 304 and forsterite, glass powders on the surface of SUS 304 and forsterite were heat-treated at $440-500^{\circ}$ Cata rate of $10^{\circ} \mathrm{C} / \mathrm{min}$ for $20 \mathrm{~min}$ under a $\mathrm{N}_{2}$ atmosphere. By applying the bonding glass, bonding between SUS 304 and forsterite was performed at $500^{\circ} \mathrm{C}$ for 10 min under a $\mathrm{N}_{2}$ atmosphere. In the process, the bonding glass was packed between SUS 304 and forsterite and was heated at a rate of $5^{\circ} \mathrm{C} / \mathrm{min}$. The thermal behavior and CTE of the glass were characterized using TG/DTA (SDT Q600, TA Instruments, U.S.A) and a dilatometer (Dil 402 C, Netzsch, EU), respectively. The microstructure and composition were analyzed by SEM/EDS (JSM-6380LV, Jeol, Japan).

\section{Results and Discussion}

Figure 2 shows the X-ray diffraction (XRD) pattern of the bonding glass. XRD patterns showed the broad peak indicating the amorphous phase. It is known that the composition with large amount of $\mathrm{PbO}$ or $\mathrm{Bi}_{2} \mathrm{O}_{3}$ can easily generate the crystalline phase but even though the total amount of second oxides as $\mathrm{PbO}$ and $\mathrm{Bi}_{2} \mathrm{O}_{3}$ was over $90 \mathrm{~mol} \%$, a glass phase was successfully fabricated by controlling the cooling rate $[9,10]$. For the glass to be utilized for bonding, itmust be somewhat fluid at the processing temperature. Differential thermal analysis ofthe glass was conducted, and the results are presented in Figure 3. The glass transition temperature $\left(\mathrm{T}_{\mathrm{g}}\right)$ was identified at $250^{\circ} \mathrm{C}$, softening occurred $\left(\mathrm{T}_{\mathrm{s}}\right)$ at $370^{\circ} \mathrm{C}$, and crystallization $\left(\mathrm{T}_{\mathrm{c}}\right)$ occurred at $490^{\circ} \mathrm{C}$ and $564^{\circ} \mathrm{C}$. With regard to the relief of stress accumulated during the cooling process, the CTE of glass should be matched with those of SUS 304 and forsterite. If we consider the structure of the gas tube in Figure 1, a larger CTE of SUS 304 compared toforsterite is more desirable to induce compressive stress upon the forsterite. This accumulated compressive stress will effectively seal the gas inside the SUS tube. Though it was not presented here, the CTE of the bonding glass was measured to be $15.9 \times 10^{-6} /{ }^{\circ} \mathrm{C}$, which is between the values of SUS $304\left(17.8 \times 10^{-6} /{ }^{\circ} \mathrm{C}\right)$ and forsterite $\left(9.9 \times 10^{-6} /{ }^{\circ} \mathrm{C}\right)$. The major difficulty in joining ceramic with metal results from the dissimilar natures of the atomic bonds between the two materials. To seal the forsterite and SUS 304 tightly with bonding glass, the glass should be able to wet both materials. Figure 4 shows the wetting behavior of the bonding glass on forsterite and SUS 304. The bonding glass showed different wetting behaviors depending on the substrates. Below $460^{\circ} \mathrm{C}$, it can be seen that the bonding glass did not wet the forsterite and SUS 304 well. When the temperature increased over $460^{\circ} \mathrm{C}$, the contact angle decreased dramatically, and the bonding glass spread on the SUS 304 like a liquid. Comparing the contact angle at $460^{\circ} \mathrm{C}$, the contact angle between the glass and SUS
304 became smaller than that between the bonding glass and forsterite. This difference behavior in contact angle depending on the kind of substrates indicates that the underlying mechanism differs significantly depending on the chemical bonding of substrates.

To investigate the chemical reaction between bonding glass and substrates, we observed the bonding interface with scanning electron microscope (SEM) and analyzed the element distribution with energy dispersive X-ray spectroscopy (EDS). Figure 5(a) shows the SEM and EDX results of bonding between glass and SUS 304. SEM image showed that the interface was flat and smooth and a tight bond was formed without void. The EDX results show that while elements from the glass were not detected inside SUS 304, as shown in spectra 3 and 2 in Figure 5(a), but interestingly a significant amount of $\mathrm{Fe}$ was detected inside the glass region, as observed in spectrum 4 in Figure 5(a). This Fe distribution in glass indicates that the elements from the glass did not diffuse into SUS 304 but the elements from SUS 304 did diffuse into the glass. Thermodynamically, metallic $\mathrm{Fe}$ is less stable than oxides such as $\mathrm{FeO}, \mathrm{Fe}_{2} \mathrm{O}_{3}$, and $\mathrm{Fe}_{3} \mathrm{O}_{4}$ in the bonding process $[11,12]$, hence metal oxide can be easily formed on the surface of SUS 304. As glass is basically a kind of metallic oxide compound and has ionic bonding nature, the iron oxide formed on the metal surface could help the glass to wet the SUS 304 and accelerate the chemical reaction with the glass. Considering that the bonding process was conducted under a $\mathrm{N}_{2}$ atmosphere, it can be inferred that oxygen for the formation of iron oxide on the SUS 304 surface should be supplied from the glass, which is a kind of metallic oxide. Luo et al. observed the borosilicate glass-Kovar bonding and explained the bonding with an oxidation-reduction mechanism [11, 12]. At the interface, the neutral metal was oxidized into metal cations by supplying free electrons to the glass. The glass, whichaccepts electrons from the metal, donates an oxygen anion to balance the charge neutrality. Then, the metal cation, i.e. $\mathrm{Fe}^{2+}$ or $\mathrm{Fe}^{3+}$ reacts with the oxygen anion to form the ionic metal oxide such as $\mathrm{FeO}, \mathrm{Fe}_{2} \mathrm{O}_{3}$ or $\mathrm{Fe}_{3} \mathrm{O}_{4}[11,13]$. For the bonding between the glass and forsterite materials, as these two materials are ionic compounds, which are composed of anions and cations, it is expected thatthe bonding glass willchemically react easily with ceramic forsterite. Figure 5(b) shows the glass and forsterite interface where the materials are bonded tightly without any voids. The interface has a rough boundary, which implies that the glass chemically reacted with forsterite. This rough interface isbeneficialin increasing the bondingstrength between the glass and forsterite. When measuring the distribution of elements, $\mathrm{Mg}$ from theforsterite was observed in all spectra, as was $\mathrm{Pb}$ or $\mathrm{Bi}$ from the glass. This elemental redistribution impliesthatthe bonding between the glass and forsterite was enabled by interchanging the elements in each material. In our previous study, we reported that metal $\mathrm{Pb}$ accelerated the bonding between $\mathrm{SiO}_{2}-\mathrm{Al}_{2} \mathrm{O}_{3}-\mathrm{R}_{2} \mathrm{O}$ ceramics and $\mathrm{PbO}-\mathrm{Bi}_{2} \mathrm{O}_{3}-\mathrm{B}_{2} \mathrm{O}_{3}-\mathrm{ZnO}-\mathrm{SiO}_{2}$ glass by forming a new crystal phase at a temperature lower than the glass transition temperature $[9,13]$. As discussed in the previous paragraph, in 
SUS 304 and glass bonding, the glass donatesan oxygen anion to accept electrons from the metal. Consequently, cations such as $\mathrm{Pb}^{2+}$ or $\mathrm{Bi}^{3+}$ in the glass are reduced to $\mathrm{Pb}$ or $\mathrm{Bi}$ metal. It was reported that even a tiny amount of $\mathrm{MgO}(100 \sim 150 \mathrm{ppm})$ dramatically reduced the surface energy of $\mathrm{Al}_{2} \mathrm{O}_{3}$ with the formation of segregates at the interface $[14,15]$. In our experiment, this reduced $\mathrm{Pb}$ or $\mathrm{Bi}$ metal reduced the surface energy of forsterite, and the glass wettedtheforsterite well, leading to tight bonding between the glass and forsterite.

In Figure 6, a schematic of the bonds between ceramic forsterite and SUS 304 with bonding glass is presented. In fact, bonds are strongly dependent on the bonding nature of materials and the bonding mechanism can be explained with the atomic transfer between two different materials. For metal-glass bonding, Fe metal donated electrons and accepted an oxygen anion from the glass to make a metal oxide. Due to the ionic bonding nature, the metal oxide on the surface of SUS 304 helped the bonding glass to wet the SUS 304. Meanwhile, for the glass-forsterite bonding, the cations in the glass were reduced by accepting electrons from the metal. This reduced metal lowered the surface energy of forsterite and accelerated the chemical reaction at a lower temperature.

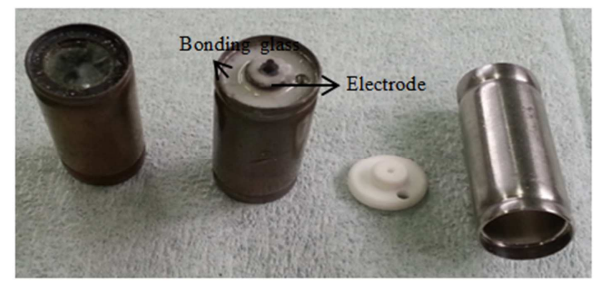

(a)

(b)

(c)

(d)

Figure 1. Photo of the ionization chamber and its components: (a) Mica window, (b) Assembled shape, (c) Forsterite piece, and (d) Body (SUS 304).

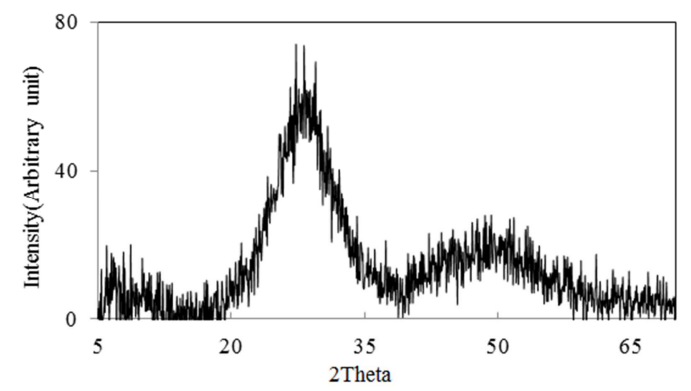

Figure 2. XRD patterns of the bonding media, 71.5PbO-24 $\mathrm{Bi}_{2} \mathrm{O}_{3}-2.5 \mathrm{~B}_{2} \mathrm{O}_{3}-1.5 \mathrm{ZnO}-0.5 \mathrm{SiO}_{2}$ (mol.\%) glass system.

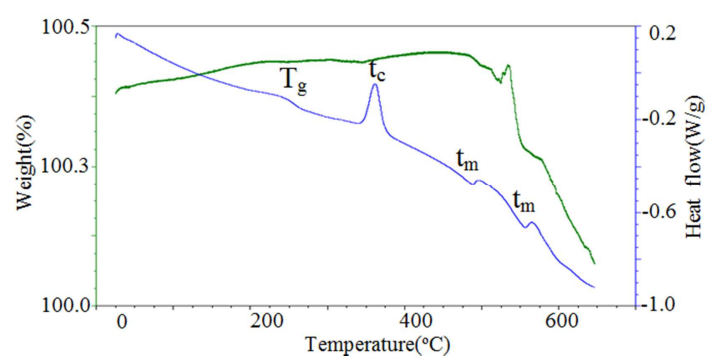

Figure. 3. Tg/DTA curves of $71.5 \mathrm{PbO}-24 \mathrm{Bi}_{2} \mathrm{O}_{3}-2.5 \mathrm{~B}_{2} \mathrm{O}_{3}-1.5 \mathrm{ZnO}-0.5 \mathrm{SiO}_{2}$ (mol.\%) glass system, where $T_{g}$, $t_{c}$, and $t_{m}$ represents the glass transition temperature, softening point, an $t_{m}$ melting temperature, respectively.

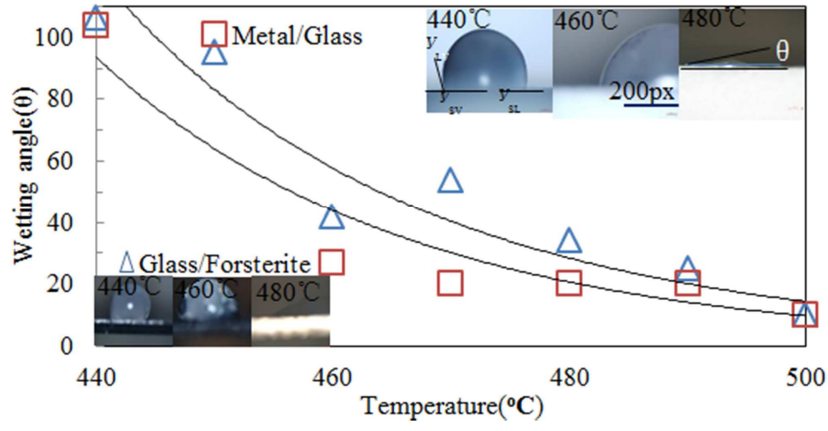

Figure 4. Contact angle of metal/glass/forsterite, and schematic diagrams of sessile drop configurations. The contact angle is identified as $\theta .440 \sim 500^{\circ} \mathrm{C}$ interval $10^{\circ} \mathrm{C}$ held for $20 \mathrm{~min}$ in a furnace containing $\mathrm{N}_{2}$.
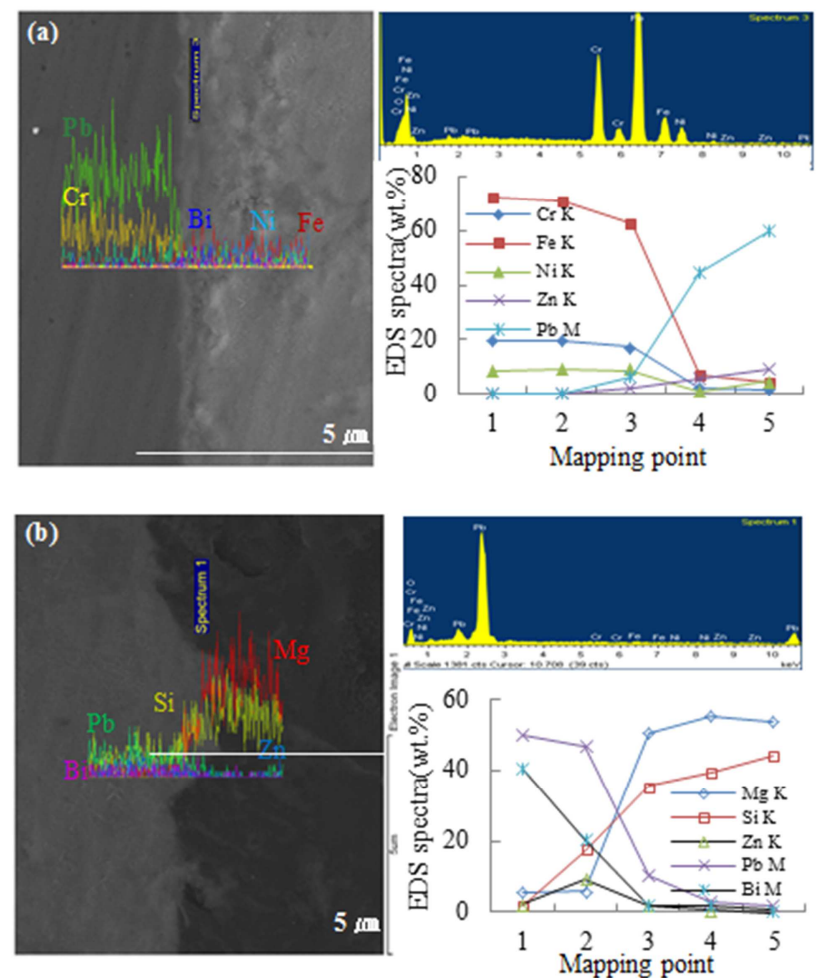

Figure 5. Cross sectional SEM and line scanning images, and EDS results (a) SUS 304/glass (b) Glass/forsterite interlayer.

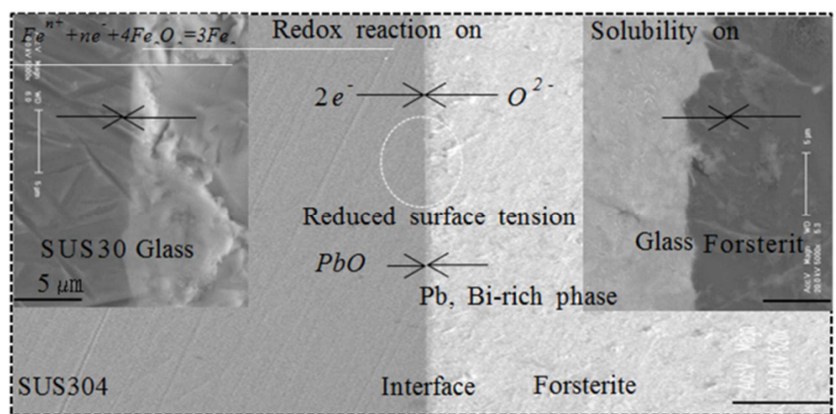

Figure 6. Schematic of the wetting and bonding mechanism between SUS 304/lead-bismate glass as bonding glass/forsterite. Left was represented SUS 304/glass side, middle was bonding glass, and right was glass/forsterite side, as determined from the SEM images, respectively. There are three figures illustrated here. 


\section{Conclusion}

The wetting and joining behaviors of 71.5PbO- $24 \mathrm{Bi}_{2} \mathrm{O}_{3}-2.5 \mathrm{~B}_{2} \mathrm{O}_{3}-1.5 \mathrm{ZnO}-0.5 \mathrm{SiO}_{2}$ in mol. $\%$ glass to achieve bonding with forsteriteceramic and SUS 304 metal were investigated to fabricate an ionization chamber. The glass transition was measured to be $250^{\circ} \mathrm{C}$, which is significantly lower than that of normal glass. The thermal expansion coefficient of the glass was $15.9 \times 10^{-6} /{ }^{\circ} \mathrm{C}$, which isbetween the values of SUS $304\left(17.8 \times 10^{-6} /{ }^{\circ} \mathrm{C}\right)$ and forsterite $\left(9.9 \times 10^{-6} /{ }^{\circ} \mathrm{C}\right)$. Due to the ionic bonding nature of glass, it easily wetted and reacted with the forsterite ceramic at temperatures of $440-500^{\circ} \mathrm{C}$. However, the wetting behavior of the glass was dependent on the temperature on SUS 304. The elemental distribution analysis and SEM images support that the high temperature accelerated the oxidation of Fe in SUS 304 , producingFeOthat bridged the bond with glass.

\section{References}

[1] L. L. Hench, R. J. Splinter, W. C. Allen, T. K. Greenlee, "Bonding mechanisms at the Interface of Ceramic Prosthetic Materials," J. Biomed. Mater. Res. A, Vol.5, No. 6, 1971, pp. 117-141.

[2] J. A. Pask, and R. M. Fulrath, "Fundamentals of Glass-to-Metal Bonding: VIII, Nature of Wetting and Adherence," J. Am. Ceram. Soc. Vol.45, No. 12, 1962, pp. 592-596.

[3] C. Sipahi, M. Özaca, "Interfacial Shear Bond Strength between Different Base Metal Alloys and Five Low Fusing Feldspathic Ceramic Systems," Dent. Mater. J. Vol. 31, No. 3, 2012, pp. 333-337.

[4] M. W. Finnis, "The Theory of Metal-Ceramic Interfaces," J. Phys.: Condens. Matter. Vol. 8, 1996, pp. 5811-5836.

[5] G. H. Stafford, "A High-Pressure Hydrogen-filled Ionization Chamber," Nature, Vol.162, 1948, pp. 771-772.
[6] J. A. Davidson, “Joining Ceramics, Glass, and Metal,"J. Mater. \& Manu. Proc. Vol. 8, 2007, pp. 267-268.

[7] T. S. Sasikala, S. Raman, P. Mohanan, C. Pavithran, M. T. Sebastian, "Effect of Silane Coupling Agent on the Dielectric and Thermal Properties of DGEBA-Forsterite Composites," J. Polym. Res. Vol. 18, No. 4, 2011, pp. 811-819.

[8] D. Simatos, G. Blond, G. Roudaut, D. Champion, J. Perez, and A. L. Faivre, "Influence of Heating and Cooling Rates on the Glass Transition Temperature and the Fragility Parameter of Sorbitol and Fructose as Measured by DSC," J. Therm. Anal. Vol. 47, No. 5, 1996, pp. 1419-36.

[9] J. Choi, D. Shin, W. Bae, and D. Jeong, "Characteristics of the $\mathrm{PbO}-\mathrm{Bi}_{2} \mathrm{O}_{3}-\mathrm{B}_{2} \mathrm{O}_{3}-\mathrm{ZnO}-\mathrm{SiO}_{2}$ Glass System Doped with $\mathrm{Pb}$ Metal Filler," J. Korean. Ceram. Soc. Vol. 50, No. 3, 2013, pp. 238-243.

[10] J. Choi, D. Shin and W. Bae, "Effect of an additive on the Physical and Electrical Properties of the $\mathrm{B}_{2} \mathrm{O}_{3}-\mathrm{ZnO}-\mathrm{Bi}_{2} \mathrm{O}_{3}$ Glass System for a Sheath Heater Module," J. Korean Ceram. Soc. Vol. 50, No. 1, 2013, pp. 57-62.

[11] W. Bergermayer, H. Schweiger, and E. Wimmer, "An Initio Thermodynamics of Oxide Surfaces: $\mathrm{O} 2$ on $\mathrm{Fe}_{2} \mathrm{O}_{3}$ (0001)," Phy. Rev. B, Vol.69, No. 19, 2004, pp. 195407-19519.

[12] D. Luo and Z. Shen, "Wetting and Spreading Behavior of Borosilicate Glass on Kovar," J. Alloy Compd. Vol. 477, No. 1-2, 2009, pp. 407-413.

[13] J. Choi, "Joining Behavior of Ceramics to Metal by Using Lead-Bismate Heavy Metal Glass Frit," J. Korean Ceram. Soc. Vol. 51, No. 4, 2014, pp. 312 316.

[14] C. Greskovich and J. A. Brewer, "Solubility of Magnesia in Polycrystalline Alumina at High Temperatures," J. Am. Ceram. Soc. Vol. 84, No. 2, 2001, pp. 420-425.

[15] W. D. Kingery, H. K. Bowen, and D. R. Uhlmann, Introduction to Ceramics, 2nd Ed. New Jersey: John Wiley \& Sons, 1976, p. 204. 